\title{
BMJ open Historical data and modern methods reveal insights in measles epidemiology: a retrospective closed
cohort study
}

\author{
Beverley J Paterson, ${ }^{1}$ Martyn D Kirk, ${ }^{2}$ A Scott Cameron, ${ }^{3}$ Catherine D'Este, ${ }^{4}$ \\ David N Durrheim ${ }^{1,5}$
}

To cite: Paterson BJ, Kirk MD, Cameron AS, et al. Historical data and modern methods reveal insights in measles epidemiology: a retrospective closed cohort study. BMJ Open 2013;3: e002033. doi:10.1136/ bmjopen-2012-002033

- Prepublication history and additional material for this paper are available online. To view these files please visit the journal online (http://dx.doi.org/10.1136/ bmjopen-2012-002033).

Received 21 September 2012 Revised 22 November 2012 Accepted 11 December 2012

This final article is available for use under the terms of the Creative Commons Attribution Non-Commercial 2.0 Licence; see http://bmjopen.bmi.com

For numbered affiliations see end of article

Correspondence to Dr. Beverley J Paterson; bev.paterson@gmail.com

\section{ABSTRACT}

Objectives: Measles was endemic in England during the early 1800s; however, it did not arrive in Australia until 1850 whereas other infectious diseases were known to have arrived much earlier-many with the First Fleet in 1788leading to the question of why there was a difference.

Design: Ships surgeons' logbooks from historical archives, 1829-1882, were retrospectively reviewed for measles outbreak data. Infectious disease modelling techniques were applied to determine whether ships would reach Australia with infectious measles cases.

Setting: Historical ship surgeon logbooks of measles outbreaks occurring on journeys from Britain to Australia were examined to provide new insights into measles epidemiology.

\section{Primary and secondary outcome measures: Serial} intervals and basic reproduction numbers $\left(R_{0}\right)$, immunity, outbreak generations, age-distribution, within-family transmission and outbreak lengths for measles within these closed cohorts.

Results: Five measles outbreaks were identified (163 cases). The mean serial interval (101 cases) was 12.3 days $(95 \% \mathrm{Cl} 12.1$ to 12.5$)$. Measles $\mathrm{R}_{0}$ (95 cases) ranged from 7.7-10.9. Immunity to measles was lowest among children $\leq 10$ years old (range $37-42 \%$ ), whereas $94-97 \%$ of adults appeared immune. Outbreaks ranged from 4-6 generations and, before 1850, were 41 and 38 days in duration. Two outbreaks after 1850 lasted longer than 70 days and one lasted 32 days.

Conclusions: Measles syndrome reporting in a ship surgeon's logs provided remarkable detail on prevaccination measles epidemiology in the closed environment of ship voyages. This study found lower measles $R_{0}$ and a shorter mean clinical serial interval than is generally reported. Archival ship surgeon log books indicate it was unlikely that measles was introduced into Australia before 1850, owing to high levels of pre-existing immunity in ship passengers, low numbers of travelling children and the journey's length from England to Australia.

\section{INTRODUCTION}

Measles was endemic in England during the early 1800 s but Australian government

\section{ARTICLE SUMMARY}

Article focus

- Previously untapped archival material, meticulously recorded by Surgeon Superintendents on-board ships travelling from Britain to Australia in the 1800 s, has been used to address the question of why measles did not reach Australia until 1850, when other infectious diseases were known to have arrived much earlier-many with the First Fleet in 1788.

- The characteristics of measles, particularly risk groups, transmission mechanism, reproductive number, length of incubation and period of communicability, resulted in measles only being introduced into Australia almost a century after European settlement.

- Political and social changes around 1850 allowed the introduction of measles into Australia.

Key messages

- Measles syndrome reporting in a ship surgeon's logs provided remarkable detail on prevaccination measles epidemiology in the closed environment of ship voyages.

- This study found lower measles $R_{0}$ and a shorter mean clinical serial interval than is generally reported.

- Archival ship surgeon log books indicate it was unlikely that measles was introduced into Australia before 1850 , due to high levels of pre-existing immunity in ship passengers, low numbers of travelling children and the journey's length from England to Australia.

Strengths and limitations of this study

- This study is the first to use historical surgeon superintendent logbooks to retrospectively review the 163 measles cases on five ships bound for Australia between 1829 and 1882 .

- The use of historical data for epidemiological analysis presents a number of challenges and there is no way to validate information recorded by individual surgeon superintendents.

- Novel historical outbreak data were used to improve our understanding of measles epidemiology; providing new insights into serial intervals and the basic reproduction number of measles. 
records suggest that measles was only introduced after 1850 despite regular shipping contact between the two countries (figure 1). ${ }^{1}$ The early absence of measles was remarkable as diphtheria, scarlet fever and whooping cough exacted a great toll on European settlers and Aboriginal Australians in early colonial times, ${ }^{1}{ }^{2}$ following the arrival of the first fleet to Australia in 1788. It has been suggested that Australia was initially protected against measles because of its high infectivity with outbreaks possibly burning out during the voyage to Australia, which could take up to 8 months. ${ }^{1-3}$ To prevent outbreaks on voyages, passengers were subjected to a medical examination and not allowed to travel if they were deemed to be harbouring an infectious disease. ${ }^{4}{ }^{5}$ However, with Britain's Whig Government assuming power (1846-1852) with a strong mandate for Free Trade and the introduction of a Bill to Repeal the Navigation Acts, 1849, British shipping lines bought faster and larger American ships to carry passengers and cargo to Australia. ${ }^{6}$ These fast clippers were introduced on the England to Australia route around 1850, shortening the journey from approximately 180 days to less than 100 days and they carried as many as 1000 passengers. ${ }^{7}$ The discovery of the Great Circle Route in this period-a non-stop southerly route from England to Australia-further shortened the journey time, while the Australian gold rush during the early 1850s resulted in a large influx of immigrants (370 000in 1852 alone $^{8}$ ). Previous limits on the number of children allowed to immigrate to Australia- a couple could not receive assisted passage if they had more than three children under 10 years of age and two under seven, were lifted in $1852 .{ }^{9}$
In the 1800s, surgeon superintendents on sea voyages to Australia recorded symptoms, treatments and outcomes of individuals by age and sex in logbooks. The sentinel features of the measles syndrome (rubeola) were well standardised in medical texts by the $1800 \mathrm{~s}^{10}$ allowing differentiation from other illnesses. In 1864, Dr Aitken accurately described measles: "The eruption in crops of a crimson rash, consisting of slightly elevated minute dots, disposed in irregular circular forms, or crescents; preceded by catarrhal symptoms for about four days, and accompanied with fever. It affects the system only once; and sometimes prevails as an epidemic. The eruption lasts six or seven days, and the whole duration of the disease is completed in from nine to twelve days". ${ }^{11}$

Disease infectivity is expressed by its basic reproduction number $\left(\mathrm{R}_{0}\right)$. Measles has an $\mathrm{R}_{0}$ of $12-18 .^{12-15}$ Serial intervals are commonly used to estimate $\mathrm{R}_{0}{ }^{16}$ and, for measles, this ranges from $6-29$ days $^{17}$ with 14 days commonly applied. ${ }^{18}$ Outbreaks linked to a single index case occurring in closed cohorts, such as island settings, ${ }^{18}$ or entirely susceptible populations have provided informative epidemiological data. A small number of historical prevaccination outbreaks provided measles parameter estimates ${ }^{10}{ }^{19-22}$ but ambiguity remains over incubation periods ${ }^{23}$ and clinical serial intervals. ${ }^{17}$ Surviving surgeon superintendents' logbooks from long voyages provide a unique historical record of medical events, effectively providing data on outbreaks in a closed cohort with a known number of susceptibles and a fixed population. These data were used to estimate measles parameters including serial intervals and basic $R_{0}$, age distributions, immunity and length and generations of outbreaks. The likelihood of measles reaching Australia before 1850 was also investigated.
Figure 1 A burial at sea*. ${ }^{*}$ November 1880, The Illustrated Australian News. Used with permission of the State Library of Victoria, Australia.

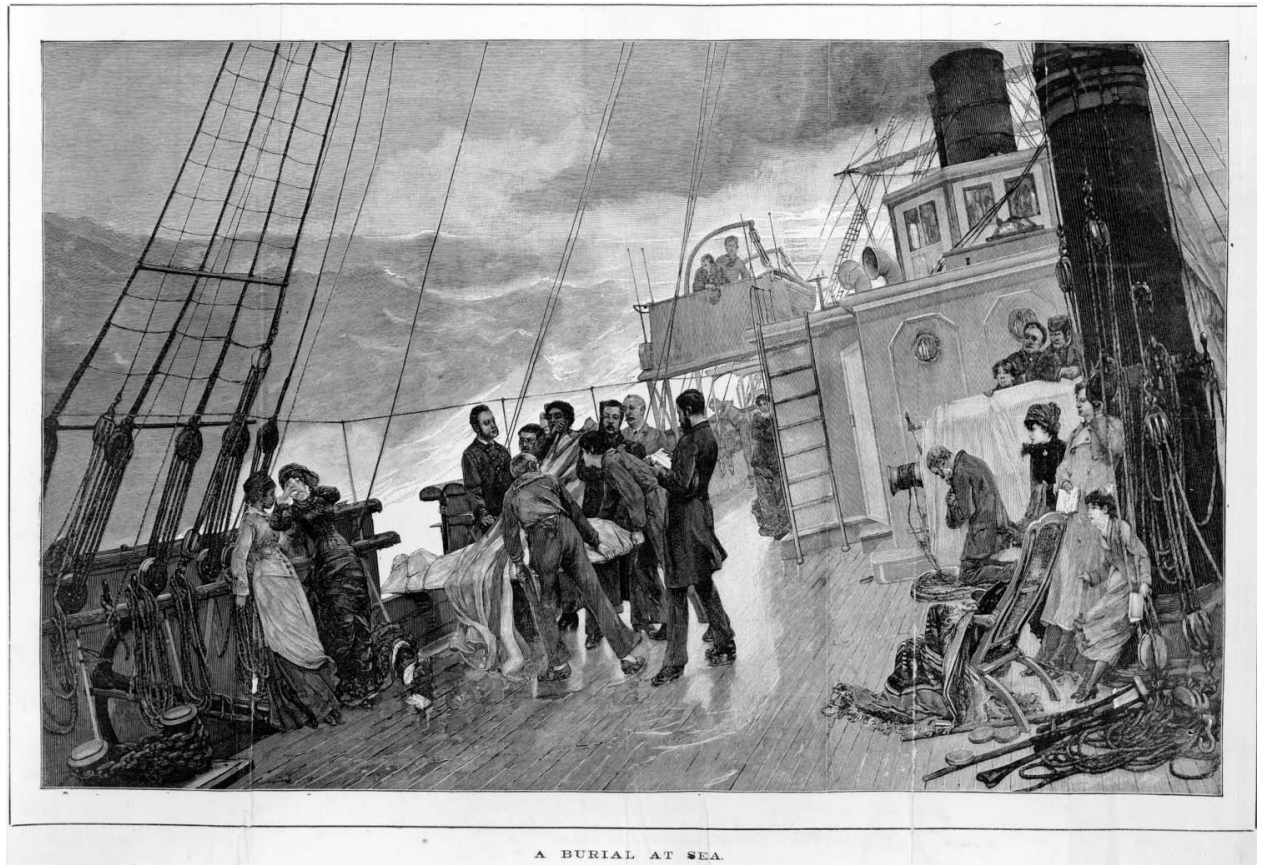




\section{METHODS}

We identified measles (rubeola) outbreaks in surgeon superintendents' logbooks for the period 1829-1882. Generally, disease cases were summarised by week of voyage, with the number and gender of passengers and crew, length of voyage and the number of children aged either less than 10 or 14 years of age. One author (BP) searched microfiche Admiralty records held under the Australian Joint Copying Project in the National Library of Australia, ${ }^{24}$ Canberra; summaries of measles outbreaks in immigrant ships papers ${ }^{25}$ held at the Adelaide Research Centre; and surgeons' reports ${ }^{26}$ located at the Sydney Records Centre. References to measles outbreaks in other archival records, including other logbooks, diaries or outbreak inquiries, were also examined. The reports or log books were incomplete and represent only a small number of voyages to Australia, hence only a small subset of measles epidemics for this period have been able to be examined. Only measles outbreaks where detailed data were available were included in the analysis.

Microsoft Excel 2003, Microsoft Excel 2007 and Stata 11 were used to calculate immunity, age distribution, case death rates, serial intervals (time between the onset of measles syndrome symptoms in one generation to the onset of symptoms in the next generation, assuming that cases were assessed soon after symptom onset ${ }^{17}$ ), generations of outbreaks, length of outbreaks, immunity levels and basic $\mathrm{R}_{0}$, separately for each cohort where a measles outbreak was identified and the required data were available.

Average serial intervals and 95\% confidence levels were calculated using individual serial intervals between each generation which contained case level data. Stata 11 was used to calculate CIs. We defined a serial interval as the time between the onset of measles syndrome symptoms in one generation to the onset of symptoms in the next generation, ${ }^{17}$ as recorded by the surgeon superintendents. It was assumed that cases were seen by the surgeon superintendent soon after onset of symptoms. Individual generations were identified by visually inspecting the data to identify separate 'waves of infection' and confirming that these were plausible by checking them to ensure that they were within the range of known measles serial intervals, which range between 6 and 29 days. ${ }^{17}$ We assumed that passengers with the same names were members of the same family group and living in close contact. Where 'family members' were infected within one serial interval range of an infected 'family member', we assumed the family member was the source of infection and used their onset date to calculate the serial interval. Cases were assigned to a 'generation' based on these data and assumptions.

Outbreak length was considered as the time between measles clinical symptom onset in the first and last cases. Owing to measles' high infectivity and the confined ship environment, we assumed that all susceptible individuals became infected during an outbreak that is, the number of susceptibles at the beginning of the outbreak was equal to the total number of cases during the outbreak. ${ }^{27}$
The basic $\mathrm{R}_{0}$ (average number of secondary cases generated by a primary case in a completely susceptible population) ${ }^{12}$ was estimated based on the assumption that the number of susceptibles and population were known. The effective reproduction number $(\mathrm{R})$ is the number of new infectious hosts in a combined population of people immune or susceptible. $\mathrm{R}$ is the product of $\mathrm{R}_{0}$ times the proportion(x) of the contacts made with susceptibles: $R=R_{0} x$. If $R_{0}=18$ for measles and $85 \%$ of the population is immune and $15 \%$ are susceptible, then the effective reproduction number is $\mathrm{R}=18 \times 0.15=2.7$. A case of measles would produce on average only 2.7 cases rather than 18 in this population. Using the Solver function in Excel and data from each outbreak, the basic $R_{0}$ was estimated by determining the values that maximised the likelihood of the entire outbreak (the product of the probabilities for each generation).

Using the outbreak data, and assuming random population mixing the probability of infection of susceptibles in each generation was estimated using the formula:

$$
\mathrm{p}(\text { infection })=1-\left(1-\left(\mathrm{R}_{0} / \mathrm{P}\right)\right)^{\mathrm{ci}}
$$

where $\mathrm{R}_{0}=$ reproduction number, $\mathrm{P}=$ ship population, and $\mathrm{ci}=$ cases in each generation (Gay NJ. Personal Communication. London: UK Health Protection Agency, 2008). The probability of infection was the probability that a susceptible individual would become infected in each generation. The risk that a susceptible individual would become infectious between time $\mathrm{t}$ and $\mathrm{t}+1$ was given by the Reed-Frost stochastic model formula $^{15}$

$$
\lambda_{\mathrm{t}}=1-(1-\mathrm{p})^{\mathrm{I}_{\mathrm{t}}}
$$

where $\lambda_{\mathrm{t}}=$ the risk that a susceptible individual becomes infected in the next time interval, $p=$ the probability that two specific individuals come into effective contact and $I_{\mathrm{t}}=$ the number of infectious individuals at timet. We assumed homogenous mixing of the ship population.

A Reed-Frost stochastic model, using the CRITBINOM and random number generation function in Excel, was used to establish the likelihood that infectious measles cases would be on a ship when it reached Australia. This model predicted the number of secondary cases in each generation and determined the likely length of each outbreak. The CRITBINOM function simulated a binomially distributed random number and introduced chance into the model. ${ }^{15}$ Parameters used in this model were the number of index cases; number of susceptible individuals; expected basic $\mathrm{R}_{0}$ (calculated in the previous step) and ship population. One thousand simulations of each outbreak were then run to determine the most likely number of generations of measles cases for these parameters. The simulation results were graphed as the probable distribution of outbreak generations relative to the voyage duration. 


\section{RESULTS}

Twenty-nine surgeons' logbooks of emigrant voyages to Australia (1837-1847), 323 immigrant ship papers (1848-1885) and six reports by ships surgeons during immigrant voyages were identified and reviewed. In addition, 160 logbooks of convict ships from 1816-1849 were briefly examined, but as most passenger lists did not include children, they would not sustain outbreaks. Five ships with detailed measles syndrome outbreak data were identified during the period 1829-1885, with a total of 163 cases (table 1). None of these ships had ports of call after leaving the British Isles and before arriving in Australia. Four of these outbreaks occurred on emigrant ships: the 'Garrow', ${ }^{28}$ the 'Roslin Castle', ${ }^{29}$ the 'Trevelyan' ${ }^{30}$ and the 'Duntrune, ${ }^{31}$ and one on the convict ship 'America'. ${ }^{32}$ The number of measles cases on each ship ranged from 6-52. Passenger and crew numbers ranged from 175-487, with voyages after 1850 having larger passenger numbers. The proportion of children on voyages ranged from $20-25 \%$.

\section{Infections by age group and sex}

Surgeons' logbooks for three ships, 'America', 'Garrow' and 'Roslin Castle', were comprehensive enough to allow detailed outbreak description, with the median age of cases being 6 years (range $<1-31$ ). Epidemic curves of the outbreaks on the 'America' (figure 2), 'Garrow' (figure 3) and 'Roslin Castle' (figure 4) display distinctive clusters of measles cases. Three cases on the 'America' were children, but no information was available on the total number of children on board. Case fatality rates could only be estimated for the 'Garrow' outbreak, where $9 \%(4 / 43)$ of cases died.

\section{Serial intervals and generations}

Serial intervals on the 'America', 'Garrow' and 'Roslin Castle' ranged from 4-20 days, with a mean of 12.3 days (95\%CI 12.1 to 12.5) (table 2). All outbreaks started with 2-3 coprimary cases rather than a single index case and lasted for 3-4 generations, with only three on the 'Roslin Castle', which had the most cases recorded $(\mathrm{n}=52)$. Based on the estimated outbreak length (70 +days) on the 'Trevelyan' and 'Duntrune' and estimated mean serial interval of 12.3 days, it is likely that there were five to six generations of measles infections during these outbreaks.

\section{Immunity to infection by age group}

Measles immunity estimates ranged from $81 \%$ to $97 \%$ among all passengers (table 1). On the 'Garrow' and the 'Roslin Castle', immunity was highest among adults with a range of 94-97\%. In children, immunity estimates ranged from $37 \%(19 / 52)$ of children under 10 years of age on the 'Garrow' to $42 \%(31 / 74)$ of children under 14 years on the 'Roslin Castle'. Both the 'Trevelyan' and 'Duntrune' had measles cases peaking in the last week of the voyage and the 'Trevelyan' had measles cases on

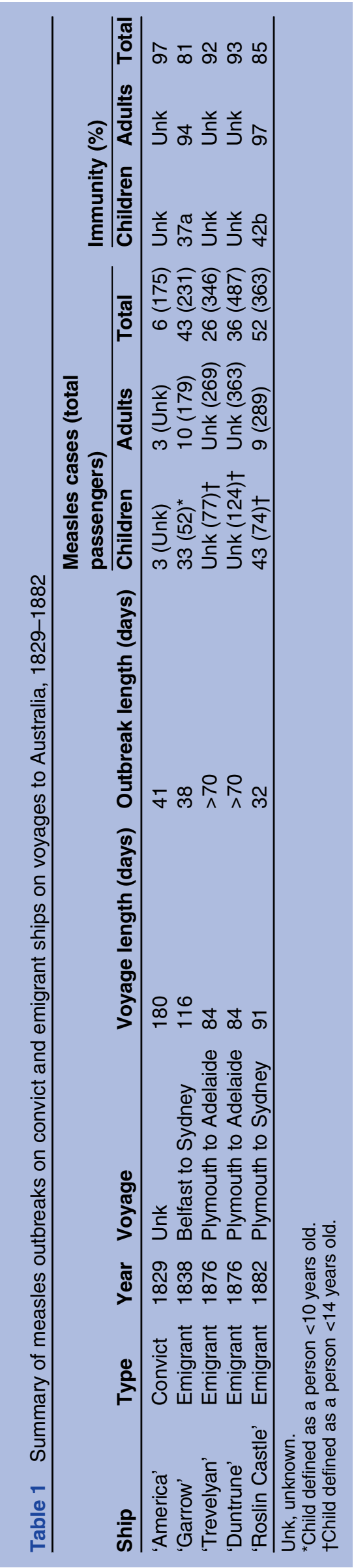


Figure 2 Measles outbreak on the ship 'America', by days of voyage, 1829.

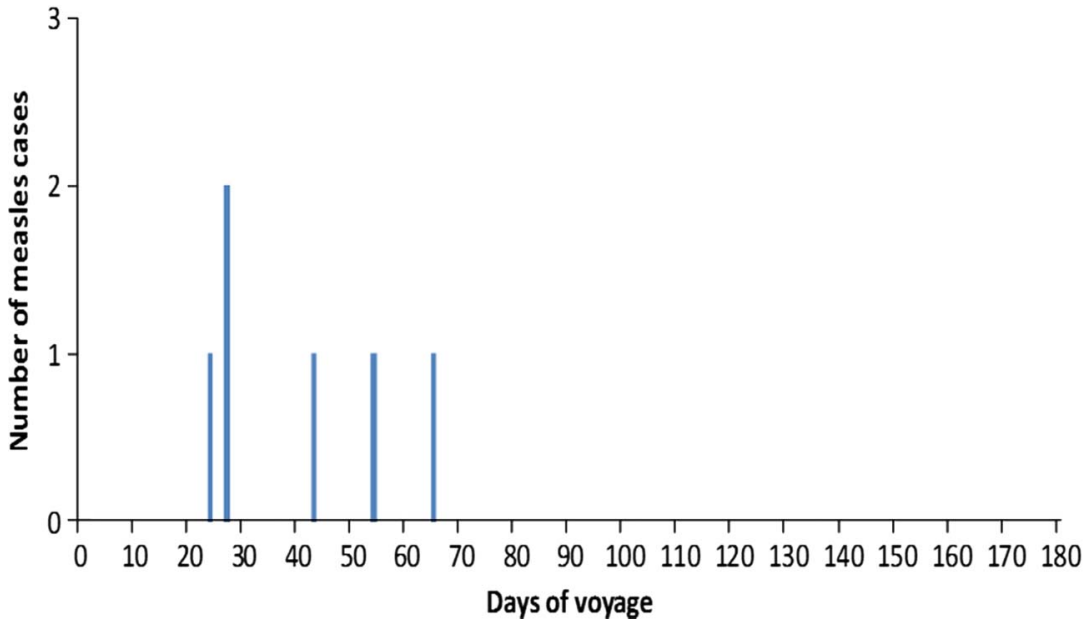

arrival in Australia suggesting that susceptibles were not exhausted during the voyage.

\section{Basic reproduction number}

$\mathrm{R}_{0}$ was calculated for the 'Garrow' and 'Roslin Castle' (table 2), being 8.7 and 10.9, respectively. It was not possible to estimate $R_{0}$ on the America because it is unknown whether the guard's children, accounting for half the cases, would have mixed with convicts hence not meeting our assumption of homogeneous mixing. Further, the $\mathrm{R}_{0}$ on the 'Trevelyan' and 'Duntrune' could not be estimated.

\section{Outbreak duration}

Outbreaks before 1850 lasted for 38 and 41 days, whereas in the late 1800 s one outbreak lasted 32 days, and two ('Trevelyan' and 'Duntrune') exceeded 70 days (with one likely continuing during quarantine in Australia). Voyages to Australia ranged from 84-180 days, with shorter journey times after 1850 .

\section{Stochastic measles outbreak modelling}

Figures 5-7 shows the modelled, possible number of outbreak generations, following the initial introduction of measles cases, as occurred during the actual voyages, and compares these to the actual length of voyage (shaded section of figures 5-7). Figure 5 shows that following the introduction of three infectious cases into the susceptible population on the 'America' in 1829, $100 \%(n=1000)$ of probable outbreaks would be less than the journey length of 180 days. Figure 6 shows that following the introduction of three infectious cases into the susceptible population on the 'Garrow' in 1838, 92\% ( $\mathrm{n}=920)$ of probable outbreaks would be less than the journey length of 116 days. Following the introduction of two infectious cases into the susceptible population on the 'Roslin Castle' in 1882, $51.5 \%(n=515)$ of probable outbreaks would be less than the journey length of 91 days (figure 7).

\section{DISCUSSION}

Despite efforts to restrict individuals and families with infectious diseases travelling on ships from Britain to Australia in the 19th century, outbreaks of infectious
Figure 3 Measles outbreak on the ship 'Garrow', by days of voyage, 1838.

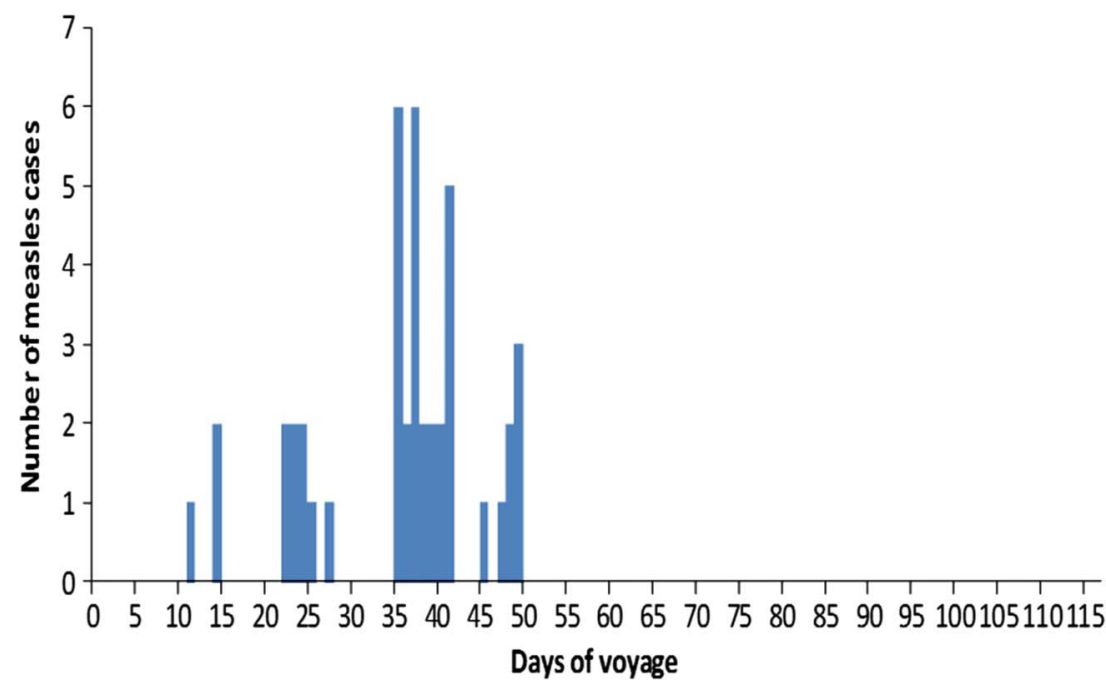


Figure 4 Measles outbreak on the ship 'Roslin Castle', by days of voyage, 1882.

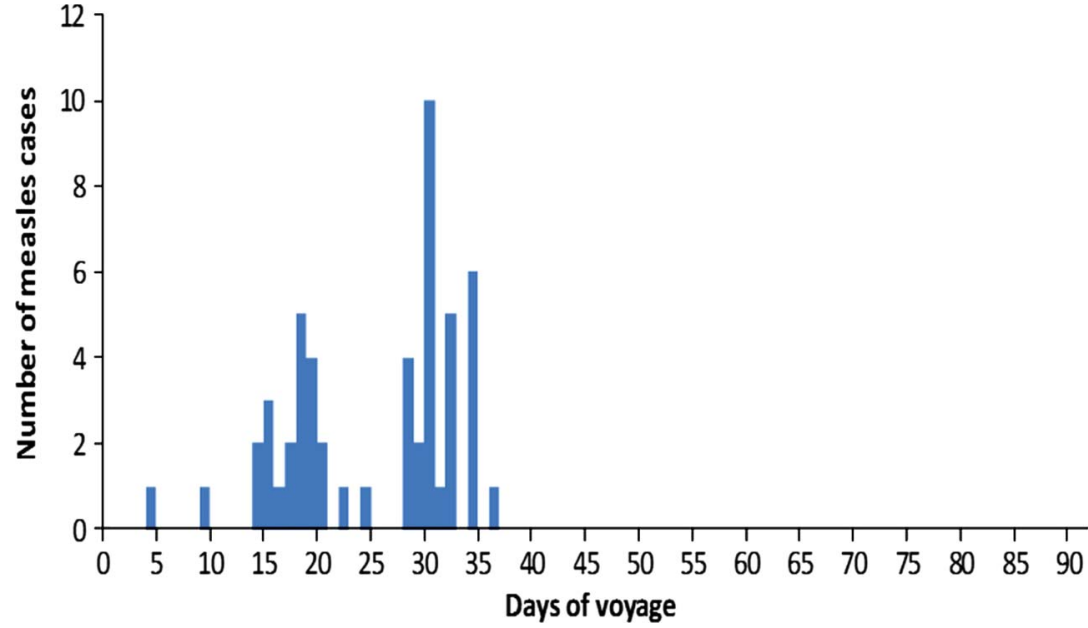

diseases, including measles, occurred on some voyages. The introduction of fast clippers able to carry up to 1000 passengers coincides with the first recorded case of measles in Australia in 1850. Cumpston ${ }^{1}$ notes extracts from the Quarantine Station in Sydney which record the increasing numbers of ships after this time who reached port with either measles cases or who had measles deaths during the quarantine period. It is likely that the briefer journey period and the greater number of passengers on board ship allowed the transmission of measles to continue throughout the journey, with some passengers continuing to be infectious on arrival in Australia. The increased numbers of child passengers following the removal of the restrictions on the number of children and the large influx of immigrants to the gold rush would also have contributed to the spread of measles.

\section{Probability of measles reaching Australia before 1850}

Cumpston $^{1}$ makes a compelling case that although measles was frequently recorded on ships before 1850 , no infectious measles cases reached Australia. The possibility of an earlier epidemic in Sydney in 1834 and in Hobart in 1835 has been suggested by Donovan, ${ }^{33}$ although there was dissension among medical practitioners at the time as to whether the disease in question was measles, scarlet fever or some other infection. Cumpston $^{1}$ notes that, from available references, there are many reports from officials documenting the lack of measles cases in the various Australian colonies. Once measles did reach Australia in 1850, the outbreaks were obvious and no longer disputed among the medical fraternity. Following its probable, initial introduction into Victoria, Australia in 1850, measles spread across the country and was recorded in New South Wales in 1853,

\begin{tabular}{|c|c|c|c|c|c|c|c|}
\hline \multirow[b]{2}{*}{ Ship } & \multirow[b]{2}{*}{ Generation } & \multicolumn{3}{|c|}{ Serial interval } & \multirow[b]{2}{*}{$\begin{array}{l}\text { Probability } \\
\text { of infection }\end{array}$} & \multirow[b]{2}{*}{$\begin{array}{l}\text { Basic } \\
\text { reproductive } \\
\text { number (R0) } \\
\text { (outbreak) }\end{array}$} & \multirow[b]{2}{*}{$\begin{array}{l}\text { Effective } \\
\text { reproductive } \\
\text { number }(R) \\
\text { (outbreak) }\end{array}$} \\
\hline & & $\begin{array}{l}\text { Days } \\
\text { into } \\
\text { voyage } \\
\end{array}$ & $\begin{array}{l}\text { Measles } \\
\text { cases }\end{array}$ & Mean $(95 \% \mathrm{Cl})$ & & & \\
\hline \multirow[t]{4}{*}{ America* $^{*}$} & 1 & $24-27$ & 3 & & 0.34 & - & - \\
\hline & 2 & 43 & 1 & 17 (12.7 to 21.3$)$ & 0.13 & - & - \\
\hline & 3 & 54 & 1 & 11 & 0.13 & - & - \\
\hline & 4 & 65 & 1 & 11 & 0.13 & - & - \\
\hline \multirow[t]{4}{*}{ Garrow } & 1 & $11-14$ & 3 & - & 0.22 & 7.1 & 1.3 \\
\hline & 2 & $22-28$ & 8 & 12 (11.2 to 13.1$)$ & 0.22 & - & - \\
\hline & 3 & $35-41$ & 25 & 13 (12.7 to 13.5$)$ & 0.54 & - & - \\
\hline & 4 & $45-49$ & 27 & $10(9.3-10.0)$ & 0.2 & - & - \\
\hline \multirow[t]{3}{*}{ Roslin Castle } & 1 & 4-9 & 2 & - & 0.05 & 10.9 & 1.6 \\
\hline & 2 & $14-24$ & 21 & $11(10.3-12.5)$ & 0.47 & - & - \\
\hline & 3 & $28-36$ & 29 & 13 (13.0-13.6) & 0.59 & - & - \\
\hline Combined voyages & $3-4$ & - & 101 & $12.3(12.1-12.5)$ & - & - & - \\
\hline
\end{tabular}




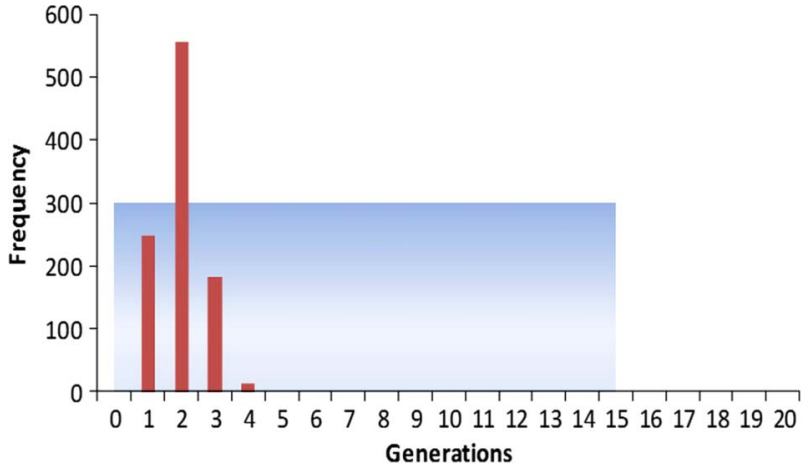

Figure 5 Simulated number of outbreaks based on the characteristics of the measles outbreaks on the ship 'America' 1829 , by the number of outbreak generations. Shaded area is the actual duration of the ship voyage (180 days).

Tasmania in 1854, Queensland in 1857, South Australia in 1859 and Western Australia in 1860. ${ }^{1}$ From 1860-1899, measles epidemics occurred simultaneously across Australia at periodic intervals which is the nature of measles epidemiology globally, once introduced into a susceptible population. These epidemics caused high death rates, particularly in the under-5-year age group. Death rates of 200-300/100 000 were common. ${ }^{1}$

The documented outbreaks of measles clinical syndrome on five ships bound for Australia between 1829 and 1882 support the hypothesis that it is unlikely that measles reached Australia before 1850. Two ships arriving post-1850 had documented cases in the final week of the voyage or on arrival, whereas none of the pre- 1850 outbreaks lasted long enough to reach Australia. Stochastic modelling reveals that voyages before 1850 were highly unlikely to have reached Australia with infectious cases of measles on board, whereas the 1882 'Roslin Castle' outbreak would have had almost a 50\% chance of arriving in Australia with infectious cases. On this ship, the hospital became full during the second generation of measles infections and further cases were treated in their own bunks. This may have resulted in a

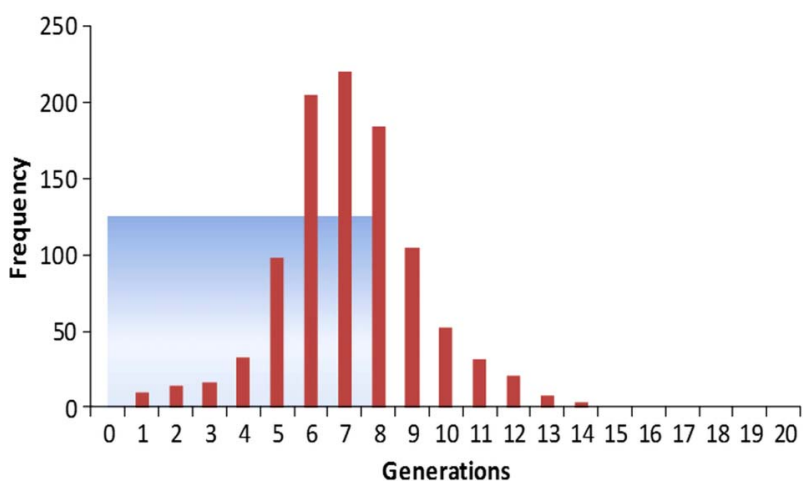

Figure 6 Simulated number of outbreaks based on the characteristics of the measles outbreaks on the ship 'Garrow' 1838 , by the number of outbreak generations. Shaded area is the actual duration of the ship voyage (116 days).

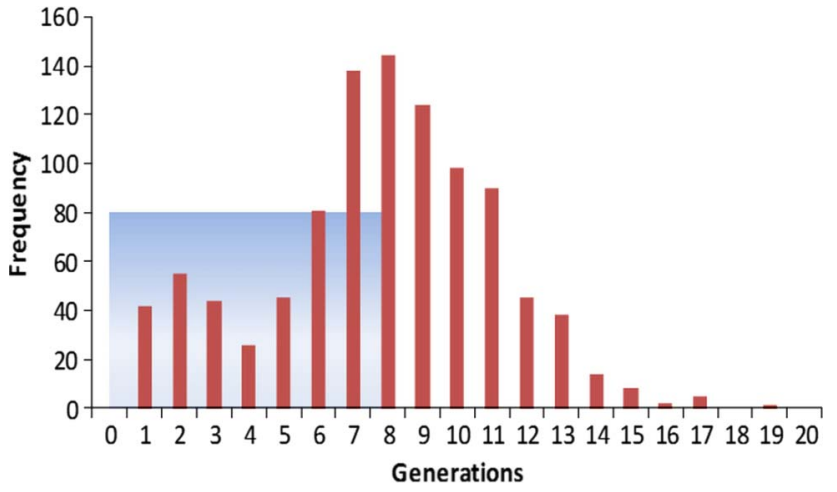

Figure 7 Simulated number of outbreaks based on the characteristics of the measles outbreaks on the ship 'Roslin Castle' 1882 , by the number of outbreak generations. Shaded area is the actual duration of the ship voyage (91 days).

shortened outbreak with susceptibles being exposed to the infection in the living quarters. Although pre-1850 voyages occasionally docked at the Cape of Good Hope, an examination of the length of six voyages in the 1830s (not reported in this study), between England, South Africa and Australia indicated that the length of each individual leg makes it unlikely that measles outbreaks would have lasted long enough on the second part of the journey to reach Australia. Earlier ships had smaller numbers of passengers and crew, including fewer children, than later voyages. The characteristics of measles, particularly risk groups, transmission mechanism, reproductive number, length of incubation and period of communicability resulted in measles only being introduced into Australia almost a century after European settlement.

\section{Immunity}

Measles virus is highly infectious, and before the availability of a measles vaccine, virtually all children were infected by the time they reached 10 years of age. ${ }^{34}$ This study confirms that the burden of measles in the 19th-century outbreaks fell on children, with the average age of infection being 6 years. The oldest case was 31 years old, indicating high immunity levels among adults. On the 'Garrow' and 'Roslin Castle', adult measles cases were rare (3-6\%), and all three adult cases (>14 years of age) on the 'Garrow' occurred in families with child cases, making within-family transmission likely.

\section{Serial intervals}

Although there is much published literature on measles, there is relatively little information available on serial intervals ${ }^{17}$ which are a key measure used in determining $\mathrm{R}_{0}$ and secondary attack rates for measles outbreaks. This study provides details of clinical onset serial intervals of a number of measles outbreaks in closed cohorts. Fine $^{17}$ notes that the parameter definitions for serial intervals in measles transmission differ between texts and that none of the references provide citable data on 
which the estimates are based. Estimates generally range between $6-29$ days ${ }^{17}$ with 14 days in common usage. In this study, the mean serial interval was 12.3 days, less than the generally applied 14 days. Ideally, serial intervals are determined where there is a single index case, which was not the situation on these voyages. On the 'America', where the second and third generations infected only one further case, the serial interval was 11 days. These findings support the view that serial intervals are shorter where individuals are in close proximity and transmission may occur earlier. ${ }^{17}$

\section{Basic reproductive number $\left(\mathbf{R}_{\mathbf{0}}\right)$}

Measles has an estimated basic $\mathrm{R}_{0}$ of $12-18$ ( refs $^{13}{ }^{15}$ ) this compares with pertussis $10-18$, polio $5-7$, HIV 2-12 and chicken pox $7-11,{ }^{12}$ making it one of the most infectious diseases known. The $\mathrm{R}_{0}$ estimated on the 'Garrow' was 7.1 and 10.9 on the 'Roslin Castle'. Lower $\mathrm{R}_{0}$ have previously been reported by Anderson and May; $\mathrm{R}_{0}$ of 5-6 for a Kansas outbreak, ${ }^{35}$ attributed to lower population density. ${ }^{36}$ In congested vessels, close proximity would likely facilitate measles transmission by aerosolised droplets, but pre-existing high levels of immunity and non-homogeneous mixing patterns could have resulted in lower $R_{0}$. Isolating infectious measles cases would reduce the contact rate between infectious individuals and susceptibles, resulting in a reduced reproduction number and making longer chains of transmission possible. Surgeon superintendents were obviously aware of measles infectivity, recording that measles cases were isolated from the rest of the ship population. This is noteworthy, given that germ theory was not accepted by the medical community until the mid-to-late 19th century.

\section{Limitations}

Using historical data for epidemiological analysis presents a number of challenges. Firstly historical records are held in a number of collections that may not be well catalogued, meaning that a comprehensive search is not possible. References to measles outbreaks were sought in a variety of archives. Reports and log books were incomplete and represent only a small number of voyages to Australia, making it difficult to generalise the results to other voyages in this time period. Some logbooks contained only summary accounts of measles outbreaks. There is no way to validate information recorded by individual surgeon superintendents. Although measles case definitions were available at the time, it is not possible to confirm consistent application by surgeons. Some measles cases may have been mild and not reported to the surgeon, or families may have deliberately hidden infectious cases. Some records were difficult to read making errors in the data possible. The precision of the $\mathrm{R}_{0}$ calculation is affected by the accuracy of the assumed number of susceptibles on board.

\section{CONCLUSIONS}

Measles syndrome reporting in ship surgeon's logs provided remarkable detail on prevaccination measles epidemiology in the closed environment of ship voyages and indicate that it was unlikely that measles was introduced into Australia before 1850, due to the relatively high level of preexisting immunity in ship passengers and crew, low numbers of children travelling and particularly the journey's length from England to Australia. Following major outbreaks of disease, including measles, on the large clippers in the mid-19th century, commissions into the health of emigrants resulted in smaller passenger numbers, hygiene improvements, lessconfined living areas, and improved ventilation on the ships. ${ }^{37}$ These improvements would have reduced the measles R0, resulting in longer outbreaks. This is an early example of disease syndrome surveillance leading to improved public health measures.

In historical analysis, this is a good illustration of social and technological changes resulting in the emergence of an infectious disease. Regular and rapid air travel has had a similar impact in the modern era, resulting in the swift transmission of infectious diseases, including measles, around the world. ${ }^{38}$

\section{Author affiliations}

${ }^{1}$ Hunter Medical Research Institute, University of Newcastle, Newcastle, New South Wales, Australia

${ }^{2}$ National Centre for Epidemiology and Population Health, The Australian National University, Canberra, Australia

${ }^{3}$ Discipline of Public Health, University of Adelaide, Adelaide, Australia

${ }^{4}$ Centre for Clinical Epidemiology and Biostatistics, University of Newcastle, University Drive, Callaghan, New South Wales, Australia

${ }^{5}$ Hunter New England Population Health, Newcastle, New South Wales, Australia

Acknowledgements We would like to thank Kieran Hosty from the Sydney Maritime Museum and Robin Haines, an Australian historian, for assistance with identifying surgeons' logs and relevant articles and books.

Contributors BP, MK and SC conceived and designed the study. BP collected the data. BP and CdE analysed the data. BP, MK, SC and DD drafted the manuscript. All authors critically revised the manuscript for important intellectual content. BP had full access to all of the data (including statistical reports and tables) in the study and can take responsibility for the integrity of the data and the accuracy of the data analysis.

Funding BP was supported by a Master of Applied Epidemiology scholarship from the Australian Government and a Hunter Medical Research Institute Research Fellowship. The study sponsors had no role in study design; in the collection, analysis and interpretation of data; in the writing of the report; or in the decision to submit the paper for publication.

Competing interests None.

Ethics approval As this is an historical analysis, ethics approval was not required for this project.

Access to the data All authors, external and internal, had full access to all of the data (including statistical reports and tables) in the study and can take responsibility for the integrity of the data and the accuracy of the data analysis.

Provenance and peer review Not commissioned; externally peer reviewed. Data sharing statement No additional data are available. 


\section{REFERENCES}

1. Cumpston JHL. The history of diphtheria, scarlet fever, measles, and whooping cough in Australia. Service publication No. 37. Canberra: Commonwealth of Australia, Department of Health, 1927.

2. Cliff A, Haggett P, Smallman-Raynor M. Measles: an historical geography of a major human viral disease from global expansion to local retreat, 1840-1990. Oxford: Blackwell Publishers, 1993.

3. Lancaster $\mathrm{HO}$. The mortality in Australia from measles, scarlatine and diptheria. Med J Aust 1952:272-6.

4. Haines R. Doctors at sea: emigrant voyages to colonial Australia. New York: Palgrave Macmillan, 2006.

5. Haines R, Shlomowitz R. Causes of death of British emigrants on voyages to South Australia, 1848-1885. Soc Hist Med 2003;16:193-208.

6. Smith CF. Ocean racers. Letchworth: Philip Allan, n.d. 1931

7. Neale RP. Racers of the deep: the yankee clippers and bluenose clippers on the Australian run 1852-1869. Melbourne: Australian Scholarly Publishing, 2007.

8. Commonwealth of Australia. The Australian gold rush. 2007; 2012 (8 June). http://australia.gov.au/about-australia/australian-story/ austn-gold-rush (accessed 8 Jun 2012).

9. Charlwood D. The long farewell: settlers under sail. Ringwood: Allen Lane, 1981.

10. Hope Simpson RE. Infectiousness of communicable diseases in the household (measles, chickenpox and mumps). Lancet 1952;2:549-54.

11. Aitken W. The science and practice of medicine v.1. 3rdedn London: Charles Griffin and Company, 1864.

12. Anderson RM, May RM. Infectious diseases of humans. Oxford: Oxford University Press, 2005.

13. Moss WJ, Griffin DE. Global measles elimination. Nature 2006;4:900-8.

14. Stillerman $\mathrm{M}$, Thalhimer $\mathrm{W}$. Attack rate and incubation period of measles. Am J Dis Child 1944;67:15-21.

15. Vynnycky E, White R, eds. An introduction to infectious disease modelling. Oxford: Oxford University Press, 2010.

16. Mercer GN, Glass K, Becker NG. Effective reproduction numbers are commonly overestimated early in a disease outbreak. Stat Med 2011;30:984-94.

17. Fine PE. The interval between successive cases of an infectious disease. Am J Epidemiol 2003;158:1039-47.

18. Rhodes CJ, Butler AR, Anderson RM. Epidemiology of communicable disease in small populations. $\mathrm{J} \mathrm{Mol} \mathrm{Med}$ 1998;76:111-16.
19. Christensen PE, Schmidt $\mathrm{H}$, Bang $\mathrm{HO}$, et al. An epidemic of measles in southern Greenland, 1951; measles in virgin soil. II. The epidemic proper. Acta Med Scand 1953;144:430-49.

20. Hope Simpson RE. The period of transmission in certain epidemic diseases: observational method for its discovery. Lancet 1948;2:755-60.

21. Panum PL Observations of the epidemic of measles on the Faroe Islands in the year 1846. New York: Delta Omega Society, 1940.

22. Goodall EW. Incubation period of measles. (Letter to the editor). BMJ 1931;1:73-4.

23. Lessler J, Reich NG, Brookmeyer R, et al. Incubation periods of acute respiratory viral infections: a systematic review. Lancet Infect Dis 2009;9:291-300.

24. $A D M 101$ series. Canberra: National Library of Australia.

25. GRG 35/48 Series. Adelaide: State Records of South Australia.

26. Reports by surgeons on health of immigrants during their passage (Medical Journals) NRS 5256. Sydney: NSW State Records.

27. Abbey $\mathrm{H}$. An examination of the Reed-Frost theory of epidemics. Hum Biol 1952;24:201-33.

28. Surgeon's Report, Garrow Emigrant Ship. Australian Joint Copying Project. Canberra: National Library of Australia, 1839.

29. Medical Report: Roslin Castle. Immigration agent. Sydney: NSW State Records, 1883.

30. GRG/35/48/1876/Trevalyn. State records South Australia. Adelaide: State Records of South Australia, 1876.

31. GRG/35/48/1876/Duntrune. State records South Australia. Adelaide: State Records of South Australia, 1876.

32. Journal of his Majesty's Convict Ship America, between 4 March and 31 August 1829. Australian Joint Copying Project. Canberra: National Library of Australia, 1829

33. Donovan JW. Measles in Australia and New Zealand, 1834-1835. Med J Aust 1970;3:5-10.

34. Pan American Health Organization. Measles elimination: field guide. Washington, DC: Pan American Health Organization, 2005.

35. Anderson RM, May RM. Infectious diseases of humans: dynamics and control. Oxford: Oxford University Press, 1992.

36. Thomas JC, Weber DJ, eds. Epidemiologic methods for the study of infectious diseases. New York: Oxford University Press, 2001.

37. Haines R. 'Little Anne is very low, Harry is in a parlous way, a great many chldren has death on their faces': mortality and its causes on voyages to colonial South Australia, 1848-1885. Adelaide: History Department, Flinders University, 2001.

38. Notes from the field: Multiple cases of measles after exposure during air travel-Australia and New Zealand, January 2011. MMWR Morb Mortal Wkly Rep 2011;60:851. 


\section{Correction}

Paterson BJ, Kirk MD, Cameron AS, et al. Historical data and modern methods reveal insights in measles epidemiology: a retrospective closed cohort study. BMJ Open 2013;3:e002033. There are two errors in this paper:

1. Under the Results heading of the abstract, the sentence "Measles R0 (95 cases) ranged from 7.7-10.9" should read "Measles R0 (95 cases) ranged from 7.1-10.9".

2. In the Results section, page 5, under the heading 'Basic Reproduction Number', line 2, the section "being 8.7 and 10.9 " should actually be "being 7.1 and 10.9".

BMJ Open 2013;3:e002033corr1. doi:10.1136/bmjopen-2012-002033corr1 